Marquette University

e-Publications@Marquette

College of Nursing Faculty Research and

Publications

Nursing, College of

$11-1-2017$

\title{
Parental Co-Construction of 5- to 13-Year-Olds' Global Self-Esteem Through Reminiscing About Past Events
}

Michelle A. Harris

University of California, Davis

M. B. Donnellan

Texas A\&M University

Jen Guo

Northwestern University

Dan P. McAdams

Northwestern University

Mauricio Garnier-Villarreal

Marquette University, mauricio.garniervillarreal@marquette.edu

See next page for additional authors

Accepted version. Child Development, Vol. 88, No. 6 (November 2017): 1810-1822. DOI. (C) 1999-2018 John Wiley \& Sons, Inc. Used with permission. 
Authors

Michelle A. Harris, M. B. Donnellan, Jen Guo, Dan P. McAdams, Mauricio Garnier-Villarreal, and Kali H.

Trzesniewski 
Marquette University

e-Publications@Marquette

\section{Nursing Faculty Research and Publications/College of Nursing}

This paper is NOT THE PUBLISHED VERSION; but the author's final, peer-reviewed manuscript. The published version may be accessed by following the link in the citation below.

Child Development, Vol. 88, No. 6 (November, 2017): 1810-1822. DOI. This article is (C) Wiley and permission has been granted for this version to appear in e-Publications@Marquette. Wiley does not grant permission for this article to be further copied/distributed or hosted elsewhere without the express permission from Wiley.

\section{Parental Co - Construction of 5 - to 13 - Year - Olds' Global Self - Esteem Through Reminiscing About Past Events}

Michelle A. Harris University of California, Davis

M. B. Donnellan

Texas A\&M University Jen Guo

Northwestern University

Dan P. McAdams

Northwestern University

Mauricio Garnier-Villarreal

Marquette University

Kali H. Trzesniewski

University of California, Davis 


\section{Abstract}

The current study explored parental processes associated with children's global self-esteem development. Eighty 5- to 13-year-olds and one of their parents provided qualitative and quantitative data through questionnaires, open-ended questions, and a laboratory-based reminiscing task. Parents who included more explanations of emotions when writing about the lowest points in their lives were more likely to discuss explanations of emotions experienced in negative past events with their child, which was associated with child attachment security. Attachment was associated with concurrent self-esteem, which predicted relative increases in self-esteem 16 months later, on average. Finally, parent support also predicted residual increases in self-esteem. Findings extend prior research by including younger ages and uncovering a process by which two theoretically relevant parenting behaviors impact self-esteem development.

Self-esteem is an important component of psychological functioning. Although it is widely studied, researchers know little about how it emerges. This is surprising given that self-esteem is associated with consequential outcomes across the life span (e.g., Trzesniewski et al., 2006). The current study reviews theoretical and empirical evidence for two established theories on self-esteem development in early childhood. Based on this evidence, a process model is proposed and tested to explain how parent-child interactions, specifically reminiscing about past events, impact self-esteem development.

Despite the lack of empirical research on the early origins of self-esteem, many theories converge on the same prediction: self-esteem is influenced by social interactions, particularly with parents during childhood. Although multiple theoretical perspectives emphasize the role of others, these approaches differ regarding hypothesized mechanisms by which others engender high self-esteem, especially with respect to social cognitive processes. One perspective is that for children to understand and explain their self-esteem, they must acquire several advanced cognitive capabilities. For instance, some theorists suggest close others impact self-esteem by providing a lens through which to view the self (e.g., Cooley, 1902; Leary, Tambor, Terdal, \& Downs, 1995; Mead, 1934). In this case, a key mechanism is the perception of others' views of self (i.e., reflected appraisals), which requires theory of mind (understanding others have thoughts different from the self; Wellman \& Lagattuta, 2000) and self-understanding (Damon \& Hart, 1982). In addition, it has been argued that children need to integrate life experiences and form a coherent view of the self before they can make a global self-evaluation (e.g., Harter, 2006). Thus, these approaches emphasize the necessity of social cognitive abilities for allowing specific interactions with others to be processed and stored (e.g., causal attributions, emotional responses). One important type of social interaction is emotional discussions of past events with parents. Conversations about significant events after emotions have subsided help children learn how to draw meaning from sensitive, self-relevant experiences and attribute the sources and implications of their emotions (see Salmon \& Reese, 2016). In this way, parents help co-construct (i.e., structure or scaffold) children's understanding of and eventual evaluation of the self (Fivush, 2011; Harter, 2006).

Other approaches suggest that self-esteem stems primarily from the affective quality of significant relationships (e.g., Sroufe, 2002). For example, attachment theory posits that warm and consistent caregiving facilitates a secure internal working model of self and other in the first year (Bowlby, 1973), which has a lasting impact on individuals well beyond infancy. The key pathway to high self-esteem, prior to advanced cognitive abilities, is through warm and 
supportive caregiving, which imparts a sense of security and acceptance to the child and teaches that he or she is loveable and worthy. Thus, this approach emphasizes that warm and supportive parenting leads to the development of high self-esteem, regardless of the quality of the parent and child conversations about emotion-laden, personal events.

Overall, there is agreement across theories that interactions with others should establish early self-esteem. However, they differ with regard to whether significant others facilitate the development of social cognitive processes important for self-esteem or whether relationships should impact high self-esteem (see also Coopersmith, 1967; Rosenberg, 1965; Shavelson, Hubner, \& Stanton, 1976). The goal of the present study is to extend prior research on the emergence and development of self-esteem by examining parent-child interactions and child self-esteem at a younger age than is usually studied and by testing an alternative, indirect, process model in addition to the link from parent-child interactions. The latter is the more common hypothesis that has received empirical attention; however, support for the link from warm and supportive parenting to high self-esteem is surprisingly sparse and difficult to detect using longitudinal designs. Nonetheless, this pathway may be easier to detect in the current study than in previous studies because we are studying parent-child dyads at earlier ages when self-esteem and the parent-child relationship dynamic are still being established.

\section{Existing Literature on Parental Influence on Self-Esteem in Childhood and} Adolescence

Existing research supports a concurrent link between parent-child relationships and child selfesteem, but few studies confirm this link over time (Harris et al., 2015). There is a robust crosssectional link between children and adolescent's self-reported self-esteem and perceived parental support, warmth, acceptance, negativity, and perceived attachment security to parents (Atzaba-Poria \& Pike, 2015; Hashimoto, Onuoha, Isaka, \& Higuchi, 2011; Lindsey, Colwell, Frabutt, Chambers, \& MacKinnon-Lewis, 2008; Parker \& Benson, 2004). To our knowledge, there is only one published study reporting the prospective relation between perceived parental warmth and global self-esteem during childhood. In a cross-lagged panel design, children from ages 7 to 11 years old who reported higher perceived parental warmth were slightly more likely to have high self-esteem 6 months later (Brummelman et al., 2015). Longitudinal research has been conducted with adolescents, but evidence is inconsistent: there are some positive links (Flynn, Cicchetti, \& Rogosch, 2014; Lam, McHale, \& Crouter, 2012), some negative links (e.g., Yang \& Schaninger, 2010), and some small or nonsignificant links between parent-child relationships and adolescent self-esteem development (Greene \& Way, 2005; Heaven \& Ciarrochi, 2008; Lam et al., 2012; Roberts \& Bengtson, 1996). All told, longitudinal findings between parent-child and parent-adolescent relationships and selfesteem are inconclusive.

One potential explanation for the inconsistent longitudinal findings is that any link from parentchild relationships to self-esteem is strongest and most detectable earlier in childhood, an age that has been rarely studied. A vast majority of the studies are conducted with adolescents, when both parental acceptance (Barber, Maughan, \& Olsen, 2005) and adolescent self-esteem (cf., Trzesniewski, Donnellan, \& Robins, 2003) are fairly stable. Parents higher in warmth and 
support in childhood might remain higher compared to their peers when children reach adolescence (i.e., rank order stability), despite changes occurring during adolescence, leading to concurrent relations but not longitudinal ones (see Barber, Stolz, Olsen, Collins, \& Olsen, 2005). To test this possibility, we will examine the relation between traditional parenting behaviors of warmth and support with self-esteem development across early and middle childhood, earlier than has typically been examined. We conceptualize affective quality of relationships as warm and supportive parenting, which aligns with what attachment theory has identified as critical aspects of helping children develop healthy self-views (Bowlby, 1973).

A second potential explanation for the inconsistent longitudinal findings in adolescence is that traditional measures of parent warmth and support may not capture the most relevant aspects of these relationships for self-esteem development. Thus, alternative assessments of parentchild relationships are needed, with the goal of understanding processes and contexts through which self-esteem is formed. We argue that a critical piece of this context, and a potential explanatory process, is the way in which parents reminisce (tell stories about the past) with their child, which serves as a means of co-constructing their child's sense of self (Fivush \& Nelson, 2006). Through this co-construction, parents teach children the cognitive skills necessary for developing healthy self-esteem (e.g., coherent self-concept, emotion understanding; Harter, 2006). That is, children's emotional competence involves decoding emotional experiences into the self-image (Denham, 2007), and parents who explain negative emotions resulting from children's self-relevant events help them interpret the event in ways that can bolster their self-esteem and teach them how to maintain their self-esteem using these techniques when faced with future negative events. Parents who ask how children were feeling when faced with a negative event create the opportunity to facilitate children's emotional competence and teach them to cope with negative emotions; for example, either by reframing their understanding of the event, focusing on positive aspects of the event, or using another coping mechanism. In this way, parents can scaffold negative thinking to be constructive and ultimately positive for children's developing self-views. Without discussion of negative emotions, these emotions could get internalized by children, potentially leaving them unprepared for coping with future negative, self-relevant events and thus unable to maintain a high level of self-esteem.

\section{Conceptual Model for Parental Co-Construction of Children's Developing Self-}

\section{Esteem}

Consistent with much of the research reviewed above, the literature on parent-child reminiscing posits that parents play a critical role in a variety of important developmental processes and outcomes (see Fivush, Haden, \& Reese, 2006). As soon as children are able to participate (often around 3 years of age), parents engage in past-event conversations with them. Throughout these conversations, parents are expert scaffolders and reinforce details of the events they believe are important for children to understand and remember (Bird \& Reese, 2006; Fivush, Gray, \& Fromhoff, 1987). In this way, children construct self-schemas from the way parents talk about personal experiences. In other words, the way in which parents reminisce about past events with their child impacts the child's emerging view of the self. 
Why would joint reminiscing impact the level of the child's self-concept and self-esteem? There are individual differences in the ways parents reminisce with their children. For example, consider an event in which a child drops his ice cream cone and feels very sad. In discussing this event at a later time, one parent might describe the event but not the related emotions and quickly move on, whereas another parent might ask how the child was feeling and discuss the causes of those emotions and what he did to feel better. This example illustrates the differences in how parents explain causes and consequences of emotions, which can teach the child how to regulate their emotions, which contributes to self-esteem maintenance (e.g., Goodall, 2015). Other individual differences include confirming and negating the child's memories, which teaches the child that others have different views from themselves, and elaborating with open-ended, leading questions, which helps the child connect past, present, and future selves (i.e., creating a personal timeline and coherent self-esteem; see Fivush, 2011). In addition to the contributions of emotion talk about both positive and negative events to children's developing understanding of the self and their relation to others, discussion of negative events is especially important for children's self-development given the greater opportunity to discuss a broad range of emotions, their causes, and consequences, and potential coping behaviors for resolving these emotions (see Fivush, Berlin, Sales, MennutiWashburn, \& Cassidy, 2003). Thus, through high-quality joint reminiscing children can learn the skills needed to develop and maintain high self-esteem.

There is preliminary support for the link between reminiscence style and self-views. Most of these researchers assess self-views using self-concept measures (e.g., trait-like descriptions of the self), with a couple researchers examining global self-esteem (e.g., evaluations of the self) directly. We examine both types of self-views in the current study. In particular, parents' use of emotion language, explanations for emotions, and confirmations of child statements are related to higher self-esteem in early childhood (Reese, Bird, \& Tripp, 2007). Next, greater use of emotion language and explanations was related to higher self-esteem in late childhood for girls but less consistently so for boys (Bohanek, Marin, \& Fivush, 2008). Finally, explanations of emotions have most consistently predicted positive self-views (Goodvin \& Romdall, 2013; Wang, Doan, \& Song, 2010). In addition, researchers have examined the consistency of selfconcepts (the extent to which children respond in a consistent manner within domains of selfconcept) and found positive relations (Bird \& Reese, 2006). In sum, although prior work linking parent-child reminiscing to self-development is promising, there are relatively few studies focused on understanding how self-esteem develops.

Beyond examining the link between parent reminiscence style and child self-views, understanding predictors of parent reminiscence style can identify another piece of the process within which children develop their self-image. There are multiple levels to personality beyond traits (see McAdams \& McLean, 2013); one level—narrative identity—is particularly relevant for predicting reminiscence style. Narrative identity is the evolving and integrative story for life (see McAdams \& McLean, 2013) that provides a sense of personal continuity through time, and there are individual differences in narrative identities (e.g., McAdams \& McLean, 2013; McAdams, Reynolds, Lewis, Patten, \& Bowman, 2001). For example, narratives can vary on the extent to which emotions are expressed and on which the causes and consequences are elaborated. In addition, individual differences in coherence involve having a life story that make sense to others and prescribes meaning to the events while integrating them into larger life 
themes (e.g., Habermas \& Bluck, 2000). One important task for the development of selfesteem is integration of life experiences into a coherent whole (e.g., Harter, 2006). Thus, parents' ability to find coherence in their own life likely impacts their ability to scaffold coherent recollections of past events with their child, which in turn should contribute to the child's high self-esteem. In sum, we propose that parent narrative identity will be related to parent reminiscence style, which will in turn contribute to child self-esteem development along with parent supportive behaviors.

Finally, our theoretical model included controls for parent-child attachment and child temperament. However, some researchers have found that mother-child attachment is strengthened through reminiscing about a shared event (e.g., Bost et al., 2006; Fivush \& Vasudeva, 2002). In addition, some researchers have conceptualized self-concept in a similar way to temperament or personality. For example, Goodvin and Romdall (2013) scored the Child Self-View Questionnaire (Eder, 1990), which is commonly used in reminiscing research focused on self-concept, into three subscales (timidity, agreeableness, negative affect). These control variables will thus be tested in exploratory analyses as outcomes of reminiscing style.

\section{Method}

\section{Participants}

One-on-one interviews were conducted with children $(N=80 ; 61 \%$ female) in the laboratory between February 2014 and December 2015. Children were between 5 and 13 years old (Mage $=7.65, S D=2.28)$. Parents were $69.7 \%$ White, $11.8 \%$ Latino/a, $10.5 \%$ Asian, and $8 \%$ another race or biracial. Seven fathers and 65 mothers (90\%) participated with their child. Thirteen percent of children were only children, $51 \%$ had one sibling, and the rest had two or more siblings. Fifty-seven percent were firstborn, $30 \%$ were second born, and the rest were third born or above. Eighty-four percent of children lived with both biological parents, $10 \%$ switched between two parents or lived with a biological and stepparent, and the rest lived with a single or adoptive parent. Interviewers were undergraduate research assistants trained by the first author.

\section{Longitudinal Subsample}

A subsample ( $n=61 ; 75 \%$ retention) participated between 3 and 32 months later $(M=16.7$, $S D=6.48$; age range $=6-14$ years old; $M=9.12, S D=2.38$ ).

\section{Measures}

\section{Child Questionnaires}

\section{Lifespan Self-Esteem scale}

The Lifespan Self-Esteem scale (LSE) consists of four items assessing global self-esteem on a 5-point scale (1 = really sad, 2 = sad, 3 = neutral, 4 = happy, 5 = really happy; see 
www.selflab.org/lse; Harris, Donnellan, \& Trzesniewski, 2017). The LSE was reliable $(\alpha=.78)$ and valid ( $r=.61, p<.05$ with Harter's Self-Perception Profile for Children; Harter, 2012).

\section{Domain-specific self-esteem}

The LSE includes domain-specific subscales for academics $(\alpha=.82)$, social $(\alpha=.80)$, athletic $(\alpha=.87)$, and physical appearance $(\alpha=.89)$. Response options and items were identical to the LSE global except for the stem. Subscales were moderately correlated with the LSE global $\left(r_{\text {academics }}=.27, r_{\text {social }}=.49, r_{\text {athletic }}=.38, r_{\text {physical }}=.49\right)$. Consistent with past reminiscing research (Reese, 2008), we created an overall average of all of the domains to create an overall self-concept score.

\section{Self-esteem consistency}

We created a self-esteem consistency scale by calculating the standard deviation of each of the LSE domain subscales and then calculating the mean consistency across the domains. Descriptive statistics $(M=0.51, S D=0.28)$ were similar to those reported for self-concept consistency in past research $(M=0.76, S D=0.07$; Bird \& Reese, 2006).

\section{Kerns' Security Scale}

We used Kerns' Security Scale (16 items; e.g., "I find it easy to trust my mom and dad"; $\alpha=.69)$ to assess children's attachment security to parents $(r=.31, p=.01$ with the LSE; Kerns, Klepac, \& Cole, 1996). We used a 5-point Likert scale (1 = not at all true for me, $5=$ really true for $\mathrm{me}$ ) with corresponding pictorial rectangles increasing in size.

\section{Observation of Parent-Child Interaction}

Parent-child reminiscing task

Parents and children discussed five emotional events in line with past studies (e.g., Fivush \& Fromhoff, 1988; Fivush \& Vasudeva, 2002; Reese, Haden, \& Fivush, 1993). The interviewer provided parents with one laminated index card for each prompt in the following order: positive, stressful, embarrassing, misbehavior, and proud, as well as one index card with examples of events in case they had trouble coming up with something to discuss (e.g., birthday parties, holidays, injuries). The interviewer instructed parents to sit with their child and talk about a one-time event when the child had experienced each emotional event and when the parent was also present. They told parents to discuss the events as they normally would if they came up in conversation, that there was no right or wrong way to discuss the events, and there was no time limit. Then, the interviewer left the room. Most conversations lasted approximately $15 \mathrm{~min}$ and were videotaped and transcribed verbatim by trained research assistants. After discussing all five events, parents completed a short questionnaire indicating when each event had occurred (month and year) and how often they had previously discussed each event with their child $(1=$ never, $5=$ very often $)$. 
Reminiscing conversations were transcribed from audiotapes verbatim. Using a codebook adapted from Fivush (1991), Fivush and Fromhoff (1988), and Reese et al. (1993), two coders rated parents' causal explanations of emotions. Coders were blind to child age and gender. Emotion talk included emotion words (e.g., happy, depressed) and behaviors (e.g., laughing, yelling). We operationalized emotional explanations as statements about the causes of emotions (e.g., "I was mad because daddy took my jeep"); interrater $r=.79-.88$. The two coders' scores were averaged for each event, and composites were averaged across positive and negative event prompts separately to result in one score for each valence.

\section{Parent Questionnaires}

\section{Parenting behaviors}

Parents rated the warmth (e.g., "Let child know you really care about him/her") and support they gave their child (e.g., "I smile at my child very often") on a scale from 1 (almost never) to 5 (almost always; Barber, Stolz, et al., 2005; Conger et al., 1992). Eighteen and 10 items were averaged for warmth $(\alpha=.79)$ and support $(\alpha=.86 ; r=.68, p<.01)$.

\section{Mini-International Personality Item Pool}

Parents rated children's personality using four items (averaged) for each of the Big Five traits on a scale from 1 (very inaccurate) to 5 (very accurate; Donnellan, Oswald, Baird, \& Lucas, 2006). Sample items are: "My child is the life of the party" ( $\alpha_{\text {extraversion }}=.63$ ) and "He or she

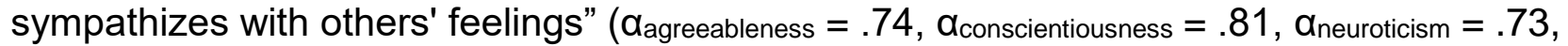
aopenness $=.73$, Mabsolute scale intercorrelation $=0.23 ; S D=0.14$, range $=0.07-0.42$, consistent with Donnellan et al., 2006).

\section{Life narratives}

Parents wrote a minimum of one paragraph about three significant life events: high point, low point, and self-defining (McAdams, 2008). They were asked to recall specific details regarding what happened at the events, who was involved, their thoughts and feelings, and why the event was meaningful or what it says about who they are as a person.

Separate research assistants from the reminiscing task coded narratives for coherence and emotional explanations using the codebook from Reese et al. (2011) and the same coding scheme from the reminiscing task. Coherence was defined as a narrative that makes sense to a naïve listener-not just in terms of understanding when, where, and what event took place, but also with respect to understanding the meaning of the event to the narrator. Three dimensions scored from 1 to 3 were summed for coherence scores: orientation (contains all necessary descriptive information for the audience to understand the story), structure (a complete story with all points making sense and in sequential order), and affect (reveals something about narrator through a lot of emotional tone through tension, humor, or pathos). Two coders independently coded 20\% of the transcripts for coherence (interrater $r=.86-.95$ ), and remaining transcripts were randomly divided between the coders. Two separate coders 
independently coded all transcripts for emotional explanations (interrater $r=.60-.78$ ). We averaged the two codes for each prompt.

\section{Procedure}

After obtaining assent and consent from the child and parent, parents completed their questionnaire on a computer while the interviewer led children to a separate room for their questionnaires. Interviewers began with a brief set of instructions and assured children that their responses would be anonymous, they did not have to answer anything they did not want to, there were no right or wrong answers, and the interviewer did not know what the child was going to say. These instructions were based on suggestions by de Leeuw (2012) for conducting survey research with young children. Sessions lasted between 1 and $1.5 \mathrm{hr}$, and families were given $\$ 10$ and a toy prize to thank them for their participation. For the longitudinal subsample, we contacted all parents from the laboratory sessions and asked if their child would be interested in participating in a 5-min follow-up survey. Children responded to the LSE over the phone with a trained interviewer.

\section{Results}

\section{Analysis Plan}

The sample consisted of 16 sibling pairs nested within families and 48 "single" children. Parents completed one questionnaire and participated in the reminiscing task separately for each child. Preliminary correlational analyses were conducted in SPSS, frequentist models were run using multilevel modeling in Mplus 7.31 (Muthén \& Muthén, 1998), and Bayesian models were conducted in $\mathrm{R}$. We transformed (by square root) reminiscing and narrative codes to account for substantial skewness with zero values. Descriptive statistics and correlations for final variables are presented in Table $\underline{1}$. We used an alpha of .05 to determine statistical significance.

Table 1. Descriptive Statistics and Pearson $r$ Correlations Among Final Variables

1. Parent narrative emotional explanations

2. Parent narrative coherence

3. Parent reminiscing emotional explanations

4. Parent support

5. Child attachment

6. Child self-esteem T1

7. Child self-esteem T2

8. Child age T1

$M(S D)$
1

2

$.48_{-}^{*}$

$.22_{-}^{*}$

$-.29 * \quad-.20$

.12

.21

.01

$-.25^{*}$

1.09

(0.84)
3

4

5

6

7

8 


\begin{tabular}{|c|c|c|c|c|c|c|c|c|}
\hline & 1 & 2 & 3 & 4 & 5 & 6 & 7 & 8 \\
\hline Skewness & -0.06 & -1.18 & 1.69 & -0.14 & -0.61 & -0.57 & -1.02 & 0.65 \\
\hline
\end{tabular}

As with other narrative and reminiscing research, the sample size is smaller than standard quantitative studies. Therefore, we conducted additional analyses from the Bayesian paradigm (see Lee \& Song, 2004; van de Schoot et al., 2014) to increase confidence in findings from the frequentist analyses. In the Bayesian framework, models are competed against each other to determine the relatively best-fitting model (i.e., absolute model fit is not estimated). This ensures alternative models are evaluated and reduces the risk of capitalizing on chance significant associations. Convergence of findings across frequentist and Bayesian methods increases confidence in the reliability of the findings. We begin with the frequentist approach and then apply the Bayesian method to our final model and one alternative model.

We used the general Bayesian software JAGS (Plummer, 2003) with its interface R package, runjags (Denwood, 2016). Convergence of the Markov chains was determined using the potential scale reduction factor, also known as univariate R-hat (see Gelman \& Rubin, 1992), and model convergence was determined when R-hat was lower than 1.10 for every parameter (Brooks \& Gelman, 1998). We implemented the Raferty and Lewis (1992) diagnostic to assure precise estimation of the credible intervals and ran the models with three chains and no thinning. We compared the models using the deviance information criteria (DIC; Gelman et al., 2013), which are estimates of the conditional log-likelihood penalized by the number of parameters. All models included multilevel regressions accounting for nesting within families.

\section{Preliminary Analyses}

We began by calculating raw correlations among the narrative and reminiscing codes. Many links between parent narrative style for their own life stories and reminiscing style with their child were significant (see Table $\underline{\mathrm{S} 1} \mathrm{a}$ and $\underline{\mathrm{S}} \mathrm{b}$ ). Contrary to expectations, we found very few statistically significant correlations between parent reminiscing and child self-esteem, domain self-esteem, or self-esteem consistency (and most of these were close to zero). Instead, we found that parent reminiscing was primarily related to child attachment (see Table $\underline{\mathbf{2}} \mathrm{a}$ and $\underline{\mathrm{S} 2 \mathrm{~b}}$ ). Based on these associations, we adjusted the model to include attachment style as an outcome of parent reminiscing style and a predictor of child self-esteem rather than as a control variable. Next, we did not find robust associations between parent reminiscing style and child personality (see Table $\underline{\mathrm{S} 2 a}$ and $\underline{\mathrm{S} 2} \mathrm{~b}$ ); thus, we excluded these variables from the final model.

We examined correlations between parenting style and the child self-view variables, and found that the parenting variables were correlated with Time 2 self-esteem and the self-esteem residual (Time 2 self-esteem controlling for Time 1 self-esteem). However, when simultaneously entered into a regression model, parent support remained significant $(\beta=.34$, $p=.04)$, whereas parent warmth did not $(\beta=.07, p=.69)$. Thus, parent support was retained for further analyses. 


\section{Frequentist and Bayesian Model Testing}

We choose one set of narrative and reminiscing variables to test the model in Figure $1 \mathrm{a}$. For both constructs, we chose explanations for negative memories because the same coding was used across methods and because emotional explanations during negative events may be more impactful than positive events on children's self-development (see Fivush et al., 2003). The model fit the data well, $X^{2}=54.28$ (11), Bayesian Information Criterion $(B I C)=607.52$; comparative fit index $(\mathrm{CFI})=1.0$, Tucker Lewis index $(\mathrm{TLI})=1.1$, root mean square error of approximation (RMSEA) $=0.00$, and all paths were significant, indicating that parents' explanations of emotions in written narratives about negative events predicted parents' explanations when reminiscing with children about negative events, which predicted children's attachment security at Time 1 . Attachment security was related to child self-esteem at Time 1 , which in turn predicted child self-esteem at Time 2. At the same time, parenting supportive behaviors predicted child self-esteem at Time 2 (Figure $1 \mathrm{~b}$ ). Given the focus on coherence in narrative memories, we also tested whether narrative coherence predicted parent explanations of negative emotion talk during reminiscing. This model also fit the data well, $X^{2}=54.17$ (11), $\mathrm{BIC}=608.80, \mathrm{CFI}=1.0, \mathrm{TLI}=1.1, \mathrm{RMSEA}=0.00$, and all paths were significant. Reporting results for every combination of narrative and reminiscing codes would be excessive, but raw data are available upon request.
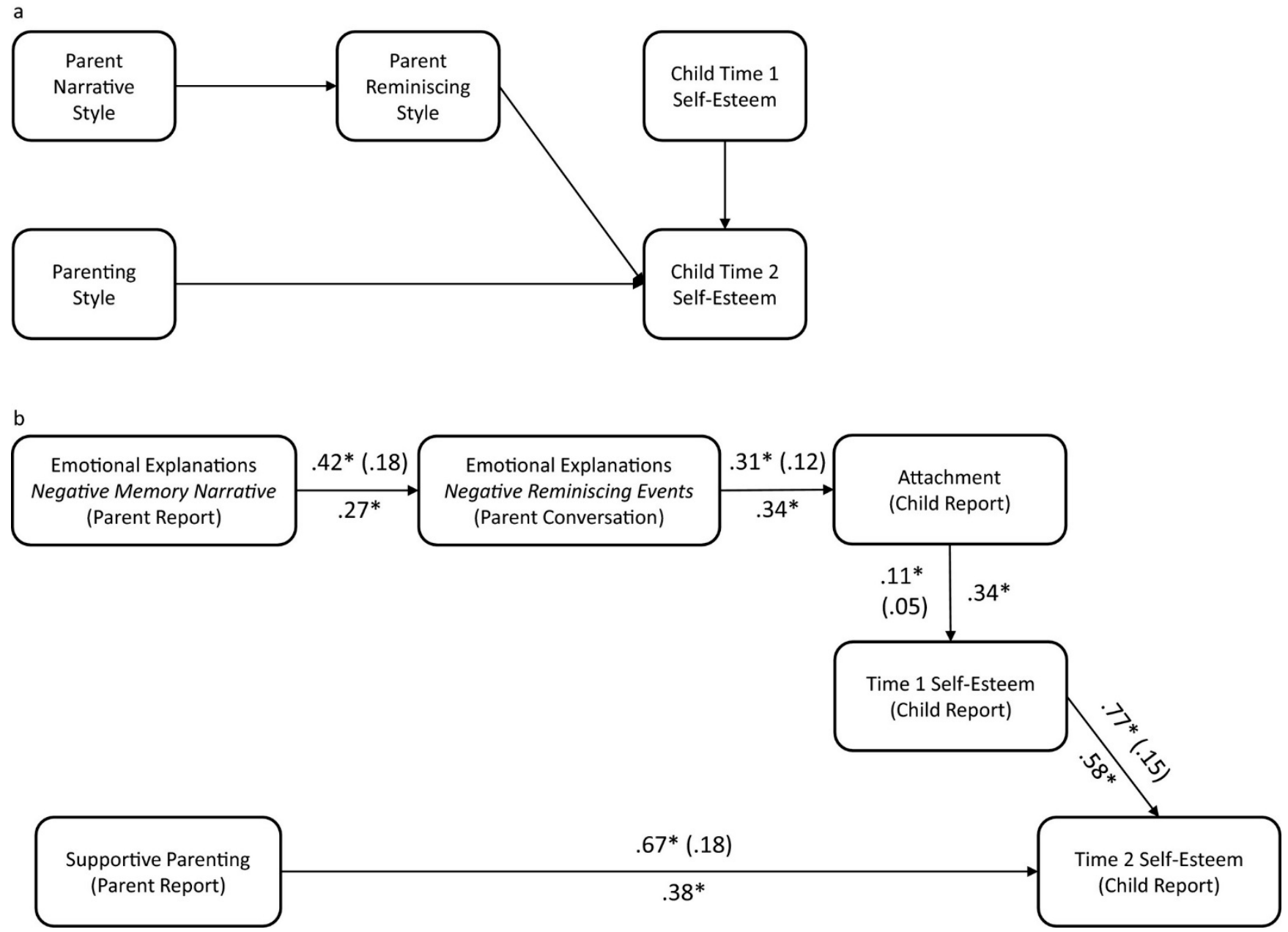


\section{Figure 1}

(a) Full conceptual model. (b) Final path model with observed effects.

Note. Unstandardized beta coefficients with standard errors in parentheses are presented above the paths and standardized beta coefficients from non multilevel model are presented below the paths.

${ }^{*} p<.05$.

Next, we tested several control variables using the model depicted in Figure $\underline{1} \mathrm{~b}$. All paths remained significant when we added the following controls: (a) length of the narrative memory on explanations given in the narrative, (b) length of the negative reminiscing conversations (i.e., parent plus child word count for negative conversations) on explanations given in the reminiscing conversation, (c) child's age on all variables in the model, (d) child's gender on all variables in the model, and (e) time lag between self-esteem assessments on Time 2 selfesteem.

For the Bayesian analyses, we tested the model from the frequentist analysis (Figure $1 \mathrm{~b}$ ) and one competing model. Model 2 estimated direct paths from each construct in Model 1 to the self-esteem residual (all predictors were allowed to correlate). We did this to determine whether the overall process or the variables on their own were important for self-esteem change. The priors for the model were weakly informative (Gelman et al., 2013), indicating that priors reduced the parameter space but do not hold enough information to guide the estimation. All intercepts followed a prior of $\alpha \sim N(1,100)$, and regression coefficients followed a prior of $\beta \sim N(0,100)$. Variances had a prior of $\sigma^{2} \sim U(0,100)$, and correlations had a prior $\rho \sim U(-1,1)$. The DIC was lower for Model 1 (1218.9) than for Model 2 (1221.9). These findings indicate the original model fit better than the competing model. Posterior distribution regression estimates were all within .10 of standardized regression coefficients from frequentist models (Figure $\underline{1} b$ ).

\section{Discussion}

The aim of the current study was to examine developmental antecedents of self-esteem during early and middle childhood. We examined parent-child co-construction of global self-esteem development through observing reminiscing conversations about significant past events with children between 5 and 13 years old. We also tested whether parent support was associated with self-esteem development in this age group that is younger than typically studied, and finally, whether parent narrative identity was related to reminiscence style.

We found many associations between aspects of parent narrative identity and reminiscence style. Although past researchers have shown that both narrative identity (Sutin \& Robins, 2005) and reminiscence style (see Fivush, 2011) are stable across contexts (e.g., event prompts, time, target characters), this is the first study to our knowledge showing links across narrative identity and reminiscence style, highlighting that patterns of recollecting events also extends across settings (i.e., individual and with the child) and formats (i.e., written and verbal). 
We failed to find support for the hypothesis that parent reminiscence style would be related to child self-esteem (i.e., global, domain, or consistency). Instead, parenting behaviors (support) were more important for the development of healthy self-esteem. This was not expected because few studies have found a longitudinal link between parenting behaviors and selfesteem. However, much of that research begins around age 13 (the oldest age in our sample). Our findings, combined with Brummelman et al. (2015), provide compelling, initial evidence that parenting behavior is a component of self-esteem development during childhood but perhaps not during adolescence (e.g., Harris et al., 2015). This raises interesting questions regarding why this might be the case. For example, one commonly held belief is that adolescents listen more to peers than parents. Experiments could be designed to test this with regard to self-esteem, such as having positive and negative self-feedback come from parents versus peers and testing which feedback impacts participants' self-evaluations as well as whether that varies by age. However, researchers should first test whether this apparent age difference holds within a single sample. That is, can this age difference in the impact of parenting be detected using the same measures of parenting and self-esteem across childhood and adolescence?

We hypothesized parent reminiscence style would be related to child self-esteem given the host of social cognitive abilities proposed as necessary for forming and verbalizing a global evaluation of the self (Harter, 2006). Parent reminiscence style is linked with several social cognitive abilities (e.g., self-understanding, theory of mind; Reese, 2002). A natural follow-up question is whether these abilities are necessary for global self-esteem, especially given that 5-year-olds can reliably report their self-esteem (Harris et al., 2017; Marsh, Craven, \& Debus, 1991). This is noteworthy because it has been argued that these social cognitive abilities take time to develop, and as a result, children cannot verbalize global self-esteem until age 8. Finding that children as young as 5, who do not yet have some of these abilities (e.g., personal timeline in autobiographical memory; Lagattuta \& Wellman, 2002), can report on their selfesteem questions the necessity of the abilities. We also failed to find age moderation in our model, which we would expect to find if early self-esteem is qualitatively different, or nonexistent.

We found links between parent reminiscence style and child attachment security, consistent with past research showing that emotional reminiscence styles facilitate children's feelings of closeness with their parent (Bost et al., 2006; Reese, 2002). In addition, child attachment security was correlated with concurrent but not later self-esteem. Previous research discusses the role of the internal working model and its enduring importance for the development of healthy self-views. Future studies could dig deeper to examine mechanisms by which parent reminiscing style facilitates attachment security, which aspects are related to self-esteem, and whether the model replicates using an observer rating of child attachment to account for the possibility of shared method variance between child attachment security and self-esteem, potentially inflating the effects found in the present study.

A natural question that emerges from this model is whether the two parenting behaviors (support and reminiscence style) are related, given that theorists have speculated such links (Darling \& Steinberg, 1993). However, in the final model, a post hoc regression from parent reminiscing emotional explanations to support was not significant $(B=.03, S E=.06, p>.25)$. 
Parent narrative emotional explanations did not predict support either $(B=-.13, S E=.08$, $p=.09$ ). Thus, at least in the current sample, the two parenting behaviors were unrelated. It could be that other dimensions of parenting (e.g., control) are more relevant for reminiscing explanations, or other types of parent reminiscence style (e.g., elaboration) are relevant for parenting behaviors, but we did not find evidence of this across our reminiscing codes and parent warmth or support. Future research could examine under what conditions reminiscing style versus warmth and support are most important for the development of the self, attachment security, and other child outcomes, and examine relevant mechanisms to uncover why each is important.

\section{Limitations and Future Directions}

Due to our multi-informant and multimethod study design, our sample size was small. Although it is comparable to past studies on parent-child reminiscing and self-esteem development in childhood, and the proposed model was partly supported by Bayesian estimations, replication in larger samples would further contribute to the model reliability.

The families in our study were mostly White and middle class, and a majority of parents were biological mothers in dual-parent homes. Our findings should be replicated with more diverse samples (e.g., Bohanek et al., 2008; Reese \& Fivush, 1993 for research with fathers). In addition, future research could examine reminiscing conversations with individuals other than parents (e.g., peers; see Gruenenfelder-Steiger, Harris, \& Fend, 2016).

Finally, there are many constructs that we envision impact the emergence and development of global self-esteem that were not tested in our model. For example, theory of mind and social comparison likely have roles in the formation of self-esteem. These were beyond the scope of the current study, but we look forward to future investigations incorporating these concepts and others with the common goal of elucidating the process of self-esteem development.

\section{References}

1 Atzaba-Poria, N., \& Pike, A. (2015). Through a cultural lens: Links between maternal and paternal negativity and children's self-esteem. Journal of Cross-Cultural Psychology, 46, 702-712. https://doi.org/10.1177/0022022115581011

2 Barber, B. K., Maughan, S. L., \& Olsen, J. A. (2005). Patterns of parenting across adolescence. New Directions for Child and Adolescent Development, 2005, 5-16. https://doi.org/10.1002/cd.124

3 Barber, B. K., Stolz, H. E., Olsen, J. A., Collins, W. A., \& Olsen, A. (2005). Parental support, psychological control, and behavioral control: Assessing relevance across time, culture, and method. Monographs of the Society for Research in Child Development, 70(Serial No. 282), 1-147.

4 Bird, A., \& Reese, E. (2006). Emotional reminiscing and the development of an autobiographical self. Developmental Psychology, 42, 613-626. https://doi.org/10.1037/0012-1649.42.4.613 
5 Bohanek, J. G., Marin, K. A., \& Fivush, R. (2008). Family narratives, self, and gender in early adolescence. The Journal of Early Adolescence, 28, 153-176. https://doi.org/10.1177/0272431607308673

6 Bost, K. K., Shin, N., McBride, B. A., Brown, G. L., Vaughn, B. E., Coppola, G., ... Korth, B. (2006). Maternal secure base scripts, children's attachment security, and mother-child narrative styles. Attachment \& Human Development, 8, 241-260. https://doi.org/10.1080/14616730600856131

7 Bowlby, J. (1973). Attachment and loss: Vol. 2. Separation. New York, NY: Basic Books.

8 Brooks, S., \& Gelman, A. (1998). General methods for monitoring convergence of iterative simulations. Journal of Computational and Graphical Statistics, 7, 434-455.

9 Brummelman, E., Thomaes, S., Nelemans, S. A., de Castro, B. O., Overbeek, G., \& Bushman, B. J. (2015). Origins of narcissism in children. Proceedings of the National Academy of Sciences of the United States of America, 112, 3659-3662. http://doi.org/10.1073/pnas.1420870112

10 Conger, R. D., Conger, K. J., Elder, G. H. J., Lorenz, F. O., Simons, R. L., \& Whitbeck, L. B. (1992). A family process model of economic hardship and adjustment of early adolescent boys. Child Development, 63, 526-541. http://doi.org/10.2307/1131344

11 Cooley, C. H. (1902). Human nature and the social order. New York, NY: Schocken Books.

12 Coopersmith, S. (1967). The antecedents of self-esteem. San Francisco, CA: W. H. Freeman.

13 Damon, W., \& Hart, D. (1982). The development of self-understanding from infancy through adolescence. Child Development, 53, 841-864. https://doi.org/10.2307/1129122

14 Darling, N., \& Steinberg, L. (1993). Parenting style as context: An integrative model. Psychological Bulletin, 113, 487-496. https://doi.org/10.1037/0033-2909.113.3.487

15 de Leeuw, E. D. (2012). Improving data quality when surveying children and adolescents: Cognitive and social development and its role in questionnaire construction and pretesting. Stengevik, Sweden: Meeting of the Advisory Scientific Board of Statistics.

16 Denham, S. A. (2007). Dealing with feelings: How children negotiate the worlds of emotions and social relationships. Cognition, Brain, Behavior, 11, 1-48.

17 Denwood, M. J. (2016). An R package providing interface utilities, model templates, parallel computing methods and additional distributions for MCMC models in JAGS. Journal of Statistical Software, 71, 1-25. https://doi.org/10.18637/jss.v071.i09

18 Donnellan, M. B., Oswald, F. L., Baird, B. M., \& Lucas, R. E. (2006). The mini-IPIP scales: Tiny-yet-effective measures of the Big Five factors of personality. Psychological Assessment, 18, 192-203. https://doi.org/10.1037/1040-3590.18.2.192

19 Eder, R. A. (1990). Uncovering young children's psychological selves: Individual and developmental differences. Child Development, 61, 849-863. https://doi.org/10.2307/1130969

20 Fivush, R. (1991). Gender and emotion in mother-child conversations about the past. Journal of Narrative and Life History, 1, 325-341. http://doi.org/10.1075/jnlh.1.4.04gen

21 Fivush, R. (2011). The development of autobiographical memory. Annual Review of Psychology, 62, 559-582. https://doi.org/10.1146/annurev.psych.121208.131702 
22 Fivush, R., Berlin, L. J., Sales, J. M., Mennuti-Washburn, J., \& Cassidy, J. (2003). Functions of parent-child reminiscing about emotionally negative events. Memory, 11 , 179-192. https://doi.org/10.1080/741938209

23 Fivush, R., \& Fromhoff, F. A. (1988). Style and structure in mother-child conversations about the past. Discourse Processes, 11, 337-355. https://doi.org/10.1080/01638538809544707

24 Fivush, R., Gray, J. T., \& Fromhoff, F. A. (1987). Two-year-old talk about the past. Cognitive Development, 2, 393-409. https://doi.org/10.1016/S0885-2014(87)80015-1

25 Fivush, R., Haden, C. A., \& Reese, E. (2006). Elaborating on elaborations: Role of maternal reminiscing style in cognitive and socioemotional development. Child Development, 77, 1568-1588. https://doi.org/10.1111/j.1467-8624.2006.00960.x

26 Fivush, R., \& Nelson, K. (2006). Parent-child reminiscing locates the self in the past. British Journal of Developmental Psychology, 24, 235-251. https://doi.org/10.1348/026151005X57747

27 Fivush, R., \& Vasudeva, A. (2002). Remembering to relate: Socioemotional correlates of mother-child reminiscing. Journal of Cognition and Development, 3(1), 73-90. https://doi.org/10.1207/S15327647JCD0301 5

28 Flynn, M., Cicchetti, D., \& Rogosch, F. (2014). The prospective contribution of childhood maltreatment to low self-worth, low relationship quality, and symptomatology across adolescence: A developmental-organizational perspective. Developmental Psychology, 50, 2165-2175. https://doi.org/10.1037/a0037162

29 Gelman, A., Carlin, J. B., Stern, H. S., Dunson, D. B., Vehtari, A., \& Rubin, D. B. (2013). Bayesian data analysis: Texts in statistical science (3rd ed.). Boca Raton, FL: Chapman \& Hall/CRC.

30 Gelman, A., \& Rubin, D. (1992). Inference from iterative simulation using multiple sequences. Statistical Science, 7, 457-472. http://dx.doi.org/10.1214/ss\%2F1177011136

31 Goodall, K. (2015). Individual differences in the regulation of positive emotion: The role of attachment and self esteem. Personality and Individual Differences, 74, 208-213. https://doi.org/10.1016/j.paid.2014.10.033

32 Goodvin, R., \& Romdall, L. (2013). Associations of mother-child reminiscing about negative past events, coping, and self-concept in early childhood. Infant and Child Development, 22, 383-400. https://doi.org/10.1002/icd

33 Greene, M. L., \& Way, N. (2005). Self-esteem trajectories among ethnic minority adolescents: A growth curve analysis of the patterns and predictors of change. Journal of Research on Adolescence, 15, 151-178. https://doi.org/10.1111/j.15327795.2005.00090.x

34 Gruenenfelder-Steiger, A., Harris, M. A., \& Fend, H. (2016). Subjective and objective peer approval evaluations and self-esteem development: A test of reciprocal, prospective and long-term effects. Developmental Psychology, 52, 1563-1577. https://doi.org/10.1037/dev0000147 
35 Habermas, T., \& Bluck, S. (2000). Getting a life: The emergence of the life story in adolescence. Psychological Bulletin, 126, 748-769. https://doi.org/10.1037/00332909.126.5.748

36 Harris, M. A., Donnellan, M. B., \& Trzesniewski, K. H. (2017). The Lifespan Self-Esteem scale: Initial validation of a new measure of global self-esteem. Journal of Personality Assessment, 1-12. https://doi.org/10.1080/00223891.2016.1278380

37 Harris, M. A., Gruenenfelder-Steiger, A. E., Ferrer, E., Donnellan, M. B., Allemand, M., Fend, H., ... Trzesniewski, K. H. (2015). Do parents foster self-esteem? Testing the prospective impact of parent closeness on adolescent self-esteem. Child Development, 86, 995-1013. http://doi.org/10.1111/cdev.12356

38 Harter, S. (2006). The self. In N. Eisenberg, R. A. Fabes, \& T. L. Spinrad (Eds.), Handbook of child psychology (Vol. 3, pp. 505-570). Hoboken, NJ: Wiley.

39 Harter, S. (2012). Self-Perception Profile For Children manual and questionnaires. Denver: University of Denver.

40 Hashimoto, S., Onuoha, F. N., Isaka, M., \& Higuchi, N. (2011). The effect of adolescents' image of parents on children's self-image and mental health. Child and Adolescent Mental Health, 16, 186-192. http://doi.org/10.1111/j.1475-3588.2011.00596.x

41 Heaven, P., \& Ciarrochi, J. (2008). Parental styles, gender and the development of hope and self-esteem. European Journal of Personality, 22, 707-724. https://doi.org/10.1002/per.699

42 Kerns, K. A., Klepac, L., \& Cole, A. (1996). Peer relationships and preadolescents' perceptions of security in the child-mother relationship. Developmental Psychology, 32, 457-466. http://dx.doi.org/10.1037/0012-1649.32.3.457

43 Lagattuta, K. H., \& Wellman, H. M. (2002). Differences in early parent-child conversations about negative versus positive emotions: Implications for the development of psychological understanding. Developmental Psychology, 38, 564-580. https://doi.org/10.1037/0012-1649.38.4.564

44 Lam, C. B., McHale, S. M., \& Crouter, A. C. (2012). Parent-child shared time from middle childhood to late adolescence: Developmental course and adjustment correlates. Child Development, 83, 2089-2103. https://doi.org/10.1111/j.1467-8624.2012.01826.x

45 Leary, M. R., Tambor, E. S., Terdal, S. K., \& Downs, D. L. (1995). Self-esteem as an interpersonal monitor: The sociometer hypothesis. Journal of Personality and Social Psychology, 68, 518-530. https://doi.org/10.1037/0022-3514.68.3.518

46 Lee, S.-Y., \& Song, X.-Y. (2004). Evaluation of the Bayesian and maximum likelihood approaches in analyzing structural equation models with small sample sizes. Multivariate Behavioral Research, 39, 653-686. https://doi.org/10.1207/s15327906mbr3904

47 Lindsey, E. W., Colwell, M. J., Frabutt, J. M., Chambers, J. C., \& MacKinnon-Lewis, C. (2008). Mother-child dyadic synchrony in European American and African American families during early adolescence: Relations with self-esteem and prosocial behavior. Merrill-Palmer Quarterly, 54, 289-315. https://doi.org/10.1353/mpq.0.0003 
48 Marsh, H. W., Craven, R. G., \& Debus, R. (1991). Self-concepts of young children 5 to 8 years of age: Measurement and multidimensional structure. Journal of Educational Psychology, 83, 377-392. http://dx.doi.org/10.1037/0022-0663.83.3.377

49 McAdams, D. P. (2008). The life story interview [Instrument]. Evanston, IL: Northwestern University.

50 McAdams, D. P., \& McLean, K. C. (2013). Narrative identity. Current Directions in Psychological Science, 22, 233-238. https://doi.org/10.1177/0963721413475622

51 McAdams, D. P., Reynolds, J., Lewis, M., Patten, A. H., \& Bowman, P. J. (2001). When bad things turn good and good things turn bad: Sequences of redemption and contamination in life narrative and their relation to psychosocial adaptation in midlife adults and in students. Personality and Social Psychology Bulletin, 27, 474-485. https://doi.org/10.1177/0146167201274008

52 Mead, G. H. (1934). Mind, self, and society from the standpoint of a social behaviorist. Chicago, IL: University of Chicago Press.

53 Muthén, L. K., \& Muthén, B. O. (1998-2012). Mplus user's guide. Los Angeles, CA: Author.

54 Parker, J. S., \& Benson, M. J. (2004). Parent-adolescent relations and adolescent functioning: Self-esteem, substance abuse, and delinquency. Adolescence, 39, 519530.

55 Plummer, M. (2003). JAGS: A program for analysis of Bayesian graphical models using Gibbs sampling. In Proceedings of the 3rd international workshop on distributed statistical computing. (1-8).

56 Raferty, A. E., \& Lewis, S. M. (1992). One long run with diagnostics: Implementation strategies for Markov chain Monte Carlo. Statistical Science, 7, 493-497.

57 Reese, E. (2002). Social factors in the development of autobiographical memory: The state of the art. Social Development, 11, 124-142.

58 Reese, E. (2008). Maternal coherence in the adult attachment interview is linked to maternal reminiscing and to children's self concept. Attachment \& Human Development, 10, 451-464. https://doi.org/10.1080/14616730802461474

59 Reese, E., Bird, A., \& Tripp, G. (2007). Children's self-esteem and moral self: Links to parent-child conversations regarding emotion. Social Development, 16, 460-478. https://doi.org/10.1111/.1467-9507.2007.00393.x

60 Reese, E., \& Fivush, R. (1993). Parental styles of talking about the past. Developmental Psychology, 29, 596-606. https://doi.org/10.1037/0012-1649.29.3.596

61 Reese, E., Haden, C. A., Baker-Ward, L., Bauer, P., Fivush, R., \& Ornstein, P. A. (2011). Coherence of personal narratives across the lifespan: A multidimensional model and coding method. Journal of Cognition and Development, 12, 424-462. https://doi.org/10.1080/15248372.2011.587854

62 Reese, E., Haden, C. A., \& Fivush, R. (1993). Mother-child conversations about the past: Relationships of style and memory over time. Cognitive Development, 8, 403-430. https://doi.org/10.1016/S0885-2014(05)80002-4

63 Roberts, R. E. L., \& Bengtson, V. L. (1996). Affective ties to parents in early adulthood and self-esteem across 20 years. Social Psychology Quarterly, 59, 96-106. http://dx.doi.org/10.2307/2787121 
64 Rosenberg, M. (1965). Society and the adolescent self-image. Princeton, NJ: Princeton University Press.

65 Salmon, K., \& Reese, E. (2016). The benefits of reminiscing with young children. Current Directions in Psychological Science, 25, 233-238. https://doi.org/10.1177/0963721416655100

66 Shavelson, R. J., Hubner, J. J., \& Stanton, G. C. (1976). Self-concept: Validation of construct interpretations. Review of Educational Research, 46, 407-441. https://doi.org/10.3102/00346543046003407

67 Sroufe, L. A. (2002). From infant attachment to promotion of adolescent autonomy: Prospective, longitudinal data on the role of parents in development. In J. G. Borkowski, S. L. Ramey, \& M. Bristol-Power (Eds.), Parenting and the child's world: Influences on academic, intellectual, and social-emotional development. Monographs in parenting (pp. 187-202). Mahwah, NJ: Erlbaum.

68 Sutin, A. R., \& Robins, R. W. (2005). Continuity and correlates of emotions and motives in self-defining memories. Journal of Personality, 73, 793-824. https://doi.org/10.1111/.1467-6494.2005.00329.x

69 Trzesniewski, K. H., Donnellan, M. B., Moffitt, T. E., Robins, R. W., Poulton, R., \& Caspi, A. (2006). Low self-esteem during adolescence predicts poor health, criminal behavior, and limited economic prospects during adulthood. Developmental Psychology, 42, 381390. https://doi.org/10.1037/0012-1649.42.2.381

70 Trzesniewski, K. H., Donnellan, M. B., \& Robins, R. W. (2003). Stability of self-esteem across the life span. Journal of Personality and Social Psychology, 84, 205-220. https://doi.org/10.1037/0022-3514.84.1.205

71 van de Schoot, R., Kaplan, D., Denissen, J., Asendorpf, J. B., Neyer, F. J., \& van Aken, M. A. G. (2014). A gentle introduction to Bayesian analysis: Applications to developmental research. Child Development, 85, 842-860. https://doi.org/10.1111/cdev.12169

72 Wang, Q., Doan, S. N., \& Song, Q. (2010). Talking about internal states in mothe-child reminiscing influences children's self-representations: A cross-cultural study. Cognitive Development, 25, 380-393. https://doi.org/10.1016/j.cogdev.2010.08.007

73 Wellman, H. M., \& Lagattuta, K. H. (2000). Developing understandings of mind. In S. BaronCohen, $\mathrm{H}$. Tager-Flusberg, \& D. J. Cohen (Eds.), Understanding other minds:

Perspectives from developmental cognitive neuroscience (2nd ed., pp. 21-49). New York, NY: Oxford University Press.

74 Yang, Z., \& Schaninger, C. M. (2010). The impact of parenting strategies on child smoking behavior: The role of child self-esteem trajectory. Journal of Public Policy \& Marketing, 29, 232-247. https://doi.org/10.1509/jppm.29.2.232 